\title{
The "faint young Sun paradox": further exploration of the role of dynamical heat-flux feed backs in maintaining global climate stability
}

\author{
Gyula I. Molnar and William J. Gutowski, JR. \\ Atmospheric and Environmental Research Inc., 840 Memorial Drive, Cambridge MA 02139-3794, U.S.A.
}

\begin{abstract}
The climate-modeling problems associated with global change underline the importance of understanding paleoclimates. The available evidence, which suggests that the Earth has never been fully glaciated, poses an especially serious problem for the early Earth when the Sun was about $20-30 \%$ fainter than today. In conventional explanations of this "faint young Sun paradox", presumed very high levels of atmospheric greenhouse gases are required to prevent runaway glaciation of the Earth. Here we explore other possible explanations of this paradox. As an extension of our previous work on this subject, we illustrate how dynamical heat-flux feed backs may have prevented the early Earth from freezing. Our simulations are carried out using a two-dimensional, seasonal-climate model with physically based parameterizations for atmospheric meridional-heat transport and sea ice. It is found that dynamical heat-flux feed backs alone may have protected the Archean Earth against a runaway glaciation to a considerable degree.
\end{abstract}

\section{INTRODUGTION}

Recent interest in global change, in particular the greenhouse warming, has prompted investigations in understanding paleoclimates as indicators of climate variability. One of the major puzzles of the Earth's history is that the global-average surface temperature has been fairly constant over geologic time scales (within about $10 \mathrm{deg}$ of the current value) even though solar luminosity was as much as $20-30 \%$ lower $4 \times 10^{9}$ years ago, according to established knowledge about stellar evolution (e.g. Newkirk, 1980).

Various climate-model simulations indicate that such a reduction of solar forcing applied to the current climate conditions would likely lead to a frozen planet. However, available evidence suggests that complete glaciation has never occurred in the past (Crowley and North, 1991), and the global-mean surface temperature was actually warmer than its present value during most of the Earth's history, thus posing the "faint young Sun paradox" (e.g. Endal and Schatten, 1982; Crowley and North, 1991). For convenience, following Lindzen and Farrel (1977), we introduce the term global stability, defined as the percentage decrease of (present-day) solar luminosity that causes total glaciation of the Earth. For example, simple zonal energy-balance models exhibit a range of $2-10 \%$ for global stability, depending on ice albedo and outgoing infrared-flux parameterizations (North and others, 1981).

Several hypotheses involving the greenhouse effect have been proposed to explain the paradox. Early explanations, using simple one-dimensional (1-D) models, used ammonia- and methane-based greenhouse scenarios (e.g. Sagan and Mullen, 1972; Hart, 1978). These were soon replaced by carbon-dioxide and watervapor-based scenarios (e.g. Owen and others, 1979; Kasting and Ackerman, 1986; Kuhn and others, 1989) because they have proved to be much more stable components of the early atmosphere.

Using a two-dimensional (latitude-height) annualmean model of the Northern Hemisphere, Molnar and Wang (1984) have shown that dynamical heat-flux feed backs associated with atmospheric vertical-heat transport (VHT) and meridional-heat transport (MHT) can also stabilize global temperatures with respect to solarluminosity decreases. More recently, Kuhn and others (1989) have combined an annual zonal energy-balance model with results from an annual 1-D radiative convective model to study the roles of MHT, greenhouse and albedo feed backs during the evolution of the Earth's surface temperature.

Early-Earth studies to date have used ice-albedo feedback parameterizations based on current climate conditions. MHT parameterizations also have been very simple or closely linked to the current climate (Molnar and Wang, 1984). We alleviate this shortcoming by applying the physically based Stone and Yao (1990) MHT parameterization in a seasonal-climate model. This parameterization allows us, for example, to investigate the effect of the time evolution of the Earth's rotation rate on global stability in a direct manner (cf. Hunt, 1979). In addition, we argue that seasonality, manifested especially in the MHT annual cycle, could also promote important feed backs for large climate perturbations. Finally, as another important improvement over earlier studies, our 
simulations include a thermodynamic sea-ice model, which avoids defining an arbitrary ice-line temperature or using ice-albedo parameterizations based on present conditions (cf. Kuhn and others, 1989).

Here, we illustrate that the feed-back mechanisms associated with VHT and MHT can help to maintain a stable climate, resisting runaway glaciation. Although, with certain ad hoc assumptions, simpler models could also show increased global stability (e.g. Lindzen and Farrel, 1977; Coakley, 1979), our conclusions may be regarded as more robust due to the physically based (i.e. valid for conditions far from the current climate) sea-ice and MHT parameterizations. Of course, some model parameterizations are still connected to the current climate. Nevertheless, so as to isolate the dynamical heat-flux feed-back effects more clearly, we do not consider here other physical changes associated with the early Earth, such as increased greenhouse-gas concentrations or oceanic-heat transport and cloud changes.

Below, we will first describe briefly the model used in the current study. Model results together with their implications will be discussed in section 3 .

\section{THE GLIMATE MODEL}

The model is an extension of the two-dimensional (2-D) annual model of Wang and others (1984) and the 2-D seasonal model of Gutowski and Molnar (1988) and Wang and others (1990). It includes three zones, representing the tropics $\left(30^{\circ} \mathrm{S}-30^{\circ} \mathrm{N}\right)$, southern extratropics $\left(30^{\circ}-90^{\circ} \mathrm{S}\right)$ and northern extratropics $\left(30^{\circ}-\right.$ $90^{\circ} \mathrm{N}$ ), with an underlying resolution of $10^{\circ}$ for processes requiring higher resolution (such as sea-ice formation). In addition, because of the large difference in thermal inertia between ocean and land surfaces, separate land and ocean sectors are included within each latitude zone. The model computes the evolution and spatial distribution of atmospheric (18 vertical layers) and ground temperatures from the heat balance for the atmosphere and the subsurface. Physically based meridional (Stone and Yao, 1990) and zonal heat-flux parameterizations are used. Surface-sensible and latent-heat fluxes are parameterized using drag laws while their vertical distribution is calculated through adjustment processes (moist-adiabatic and baroclinic). The seasonal model uses the same sophisticated radiative parameterizations as the 2-D annual model. Water-vapor mixing ratios are calculated by prescribing the observed seasonal cycle of relative humidity. Cloud amounts and altitudes are fixed at their observed annual cycle in the model version used for this study. As a consequence, the model's sensitivity to forcing perturbations is lower than that of some other models: for example, doubling atmospheric $\mathrm{CO}_{2}$ produces a $1.8 \mathrm{deg}$ increase in global-mean annual surface-air temperature.

For the current investigation, probably the most important improvement over earlier model versions is that the ice-albedo feed back is parameterized using a thermodynamic sea-ice model. It is based on Semtner's (1976) onelayer thermodynamic ice model, as modified for large-scale (coarse horizontal resolution) 2-D models (Peng and others, 1987). Similar models have been the basis for ice modeling in many general-circulation models (GCMs). In the seasonal model the extratropics in each hemisphere are represented by two boxes, one for land and one for ocean. We subdivide the ocean part of the box into zones $10^{\circ}$ of latitude wide and compute ice separately for each zone. Note that surface emission as well as sensible- and latentheat fluxes are computed explicitly at this $10^{\circ}$ resolution, whilst downward shortwave and longwave radiative fluxes are determined for each $10^{\circ}$ zone using the appropriate 3 mode Legendre polynomial expansion (cf. North and others, 1981). Ice can occupy a fraction $f_{\mathrm{i}}$ of the zone with thickness $h_{\mathrm{i}}$. The surrounding ocean has a zone-average, mixed-layer temperature $T_{\mathrm{o}}$. The mixed-layer thickness is kept constant at $50 \mathrm{~m}$ for all model experiments.

We assume that within each zone there is a range of ocean temperatures about the mean. If the net heat balance for the zone's ocean is negative, then all temperatures are reduced by the same amount. Parts of the zone that would fall below freezing point are held at freezing point, with the needed heat coming from ice formation. When heat is gained, we assume that ocean temperatures at freezing point represent water in contact with ice. This part of the heating goes into ice melt rather than water warming. These changes affect the ice fraction $f_{\mathrm{i}}$. The model also computes vertical thickness changes in ice according to the net heat lost or gained by energy exchange with the atmosphere above and the ocean directly below. To complete the modeling, we retain in our computation an ocean heat transport using the "qflux" method of the Goddard Institute for Space Studies (GISS) GCM (Hansen and others, 1983), wherein an ocean flux is obtained from energy-balance requirements in a control run that uses specified ocean temperature and ice volume in each zone, based on observations.

The snow cover is parameterized according to Robock (1980). The seasonally varying hemispheric-snow extents are in good agreement with observations. The modelcalculated seasonal variation of the atmospheric temperature structure, heat fluxes and planetary and surface albedos are also in good agreement with available observations. A more detailed description of the model (apart from the sea-ice model) can be found in Wang and others (1990).

\section{RESULTS AND DISGUSSION}

The physically based thermodynamic sea-ice parameterization is an improvement over earlier studies of global stability, so a reasonably accurate representation of the current seasonal distribution of ice cover is important. Figure 1 shows the model-calculated Northern Hemispheric ice cover as a function of time of the year, together with the GISS GCM-calculated values and the Robock (1980) observational data. Although the model somewhat underestimates the spring ice cover, the maximum and minimum values are well-simulated. Note that the Southern Hemispheric ice cover exhibits an even better agreement with observations.

In order to assess the global stability of the present climate, we have perturbed the current climate state with gradually decreasing solar-constant values. In the present study we use the same solar-constant evolution scenario as Kuhn and others (1989): 20\% lower solar luminosity 


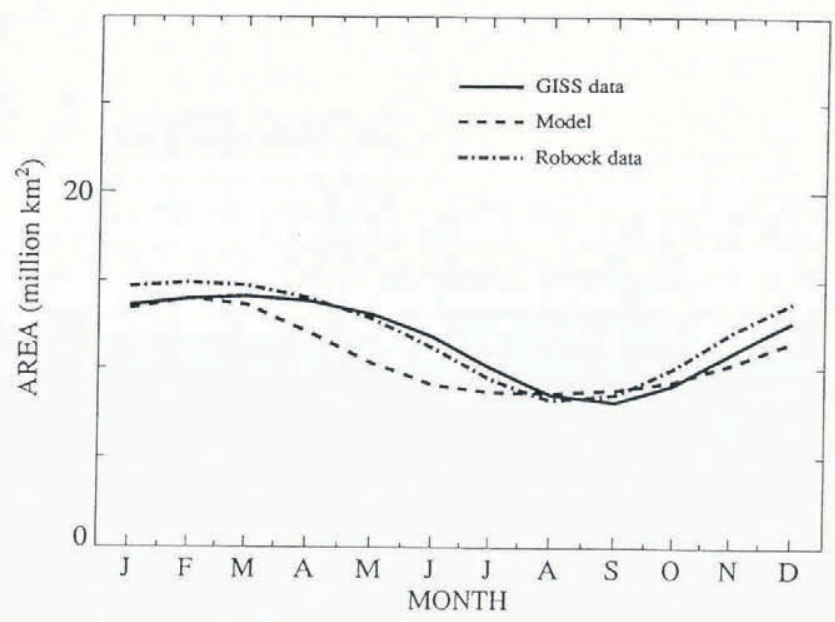

Fig. 1. Model-calculated and observed Northern Hemispheric ice-cover area as a function of time of the year.

$4 \times 10^{9}$ years ago, with a linearly increasing luminosity from then to the present. In order to study the effects of dynamical heat fluxes and their feed backs on global stability, we ran the model with all dynamical heat-flux feed backs included and without these feed backs. For example, the fixed-MHT case means that the annual cycle of the meridional dynamical heat flux is fixed at its control climate value (i.e. the model is run without the MHT feed back).

Figures 2 and 3 summarize the results of our globalstability experiments in terms of Northern Hemispheric ice cover. Figure 2 shows the seasonal cycle of sea-ice extent for selected solar-luminosity decreases. Figure 3 shows the fractional ice cover of the Northern Hemisphere's extratropical zone, for the boreal winter and summer, respectively. Cases of fixed MHT, fixed VHT and fixed VHT + MHT are not shown, since, the global stability was found to be less than $1 \%$. The global stability for the all-feed-backs case was $17.4 \%$. Actually the global stability could be somewhat higher, since the above percentages indicate the onset of a "runaway glaciation", not a stable "white-Earth" solution. This

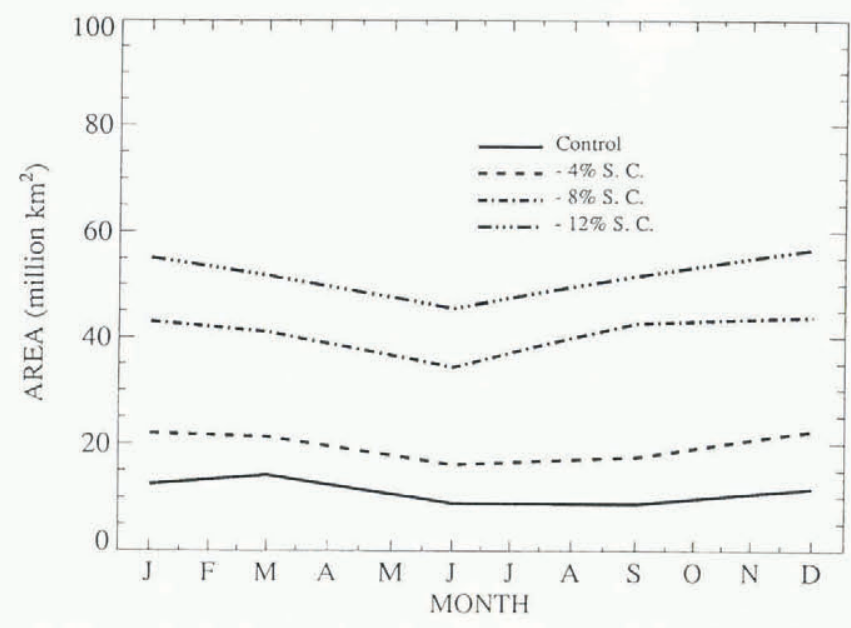

Fig. 2. Northern Hemispheric ice extent for selected solarluminosity decreases as a function of time of the year. S.C., solar constant. runaway glaciation started when mean tropical surfaceair temperature fell below freezing but the mean tropical ocean mixed-layer temperature was still above freezing by a few tenths of a degree. Moreover, in the southern extratropical zone the sea-ice fraction did not quite reach the value of 1 by the time the northern zone's runaway glaciation started, and made further runs with even smaller solar-constant values numerically impossible.

The seasonal model's global-stability values are only partly similar to those found in our previous annualmodel study (Molnar and Wang, 1984). The annual model exhibited a $21 \%$ global stability for the all-feedback case, $26 \%$ for fixed MHT, and less than $1 \%$ for fixed VHT and fixed MHT + VHT. The most notable difference between the annual and seasonal model results is the large global stability in the annual fixed-MHT case vs the unstable situation in the seasonal model. In the annual-model case, fixed MHT produces significant tropical cooling first, with little or no change in the ice cover until the temperature at most latitudes falls below the "ice-line" temperature, which occurs when the solarconstant reduction reaches about $25 \%$. In the present study, it appears that model seasonality in combination with a physical sea-ice submodel and the use of a physically based MHT parameterization leads to a different behavior: the global stability is much less (actually the climate is subject to runaway glaciation even for a $1 \%$ solar-constant decrease) for fixed MHT than for the all-feed back case. Further experiments were carried out to establish whether the physical vs empirical MHT, the physical vs empirical ice-albedo parameterization or model seasonality is the most important factor. The results revealed that seasonality is the key in explaining the runaway glaciation for the fixed-MHT case. Essentially, the seasonal cycle itself is a very large perturbation for the extratropical zones, and by not allowing the poleward atmospheric-heat transport to respond, even small perturbations became "fatal". Nevertheless, the current results confirm the annual model's finding that the VHT feed back (essentially convection) is crucial in maintaining a large value for global stability.

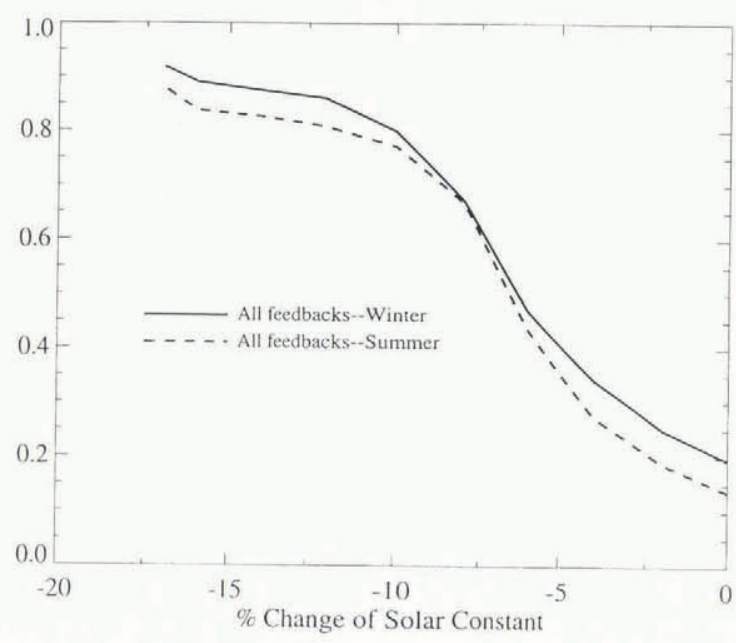

Fig. 3. Fractional ice cover of the Northern Hemisphere's extratropical zone as a function of solar-constant change for the boreal winter and summer 
Finally, we mention that we also performed an experiment to estimate the degree of additional increase of global stability due to the significantly smaller landmass areas in the Archean. Using present-day conditions but lessening land fraction in each latitude belt to $5 \%$, a global mean surface-temperature increase of $3.9 \mathrm{deg}$ was found, which would significantly increase global stability. Note that a very similar value (4 deg) was found in one of the first GCM studies of Precambrian climate for an allocean Earth (Jenkins and others, 1993), which lends more credibility to our global-stability simulations using a simpler model.

In summary, the model results suggest that the dynamical heat-flux feed backs alone could have played an important role in maintaining a rather high globalstability value against total glaciation over most of the geological time-scale. However, there is a caveat requiring further study; in addition to atmospheric MHT, there is an oceanic poleward heat transport, and the experiments performed so far used oceanic MHT characteristic of the current climate. We plan to examine the effect of this treatment on the value of global stability in the future.

\section{ACKNOWLEDGEMENTS}

This research was supported by the Atmospheric and Climate Division, U.S. Office of Health and Environmental Sciences, the U.S. Department of Energy and the Climate Dynamics Program of the U.S. National Science Foundation. The authors also thank K. Heroy for important data assimilation and programming help.

\section{REFERENCES}

Coakley, J.A., Jr. 1979. A study of climate sensitivity using a simple energy balance climate model. f. Atmos. Sci., 35, 260-269.

Crowley, T.J. and G. R. North. 1991. Paleoclimatology. Oxford, etc., Oxford University Press. (Oxford Monographs on Geology and Geophysics, 18. .

Endal, A.S. and K.H. Schatten. 1982. The faint young sun-climate paradox: continental influences. 7. Geophys. Res., 87 (C9), 7295-7302. Gutowski, W.J., Jr and G. Molnar. 1988. Accelerating the convergence of seasonal climate models with mixed layer oceans. 7. Geophys. Res., 93 D2), 1737-1744.

Hansen, J. and 7 others. 1983. Efficient three-dimensional global models for climate studies: models I and II. Mon. Weather Rev., 111, 609-662.

Hart, M. H. 1978. The evolution of the atmosphere of the Earth. Icarus, 33, $23-29$

Hunt, B. G. 1979. The influence of Earth's rotation rate on the general circulation of the atmosphere. 7. Atmos. Sci., 36, 13921408.

Jenkins, G.S., H. G. Marshall and W.R. Kuhn. 1993. Precambrian climate: the effects of land area and Earth's rotation rate. 7 . Geophys. Res., 98, 8785-8791.

Kasting, J. F. and T. P. Ackerman. 1986. Climatic consequences of very high carbon dioxide levels in the Earth's early atmosphere. Science, 234, 1383-1385.

Kuhn, W. R., J. C. G. Walker and H. G. Marshall. 1989. The effect on Earth's surface temperature from variations in rotation rate, continent formation, solar luminosity, and carbon dioxide. $f$. Geophys. Res., 94(D8), 11,129-11,136.

Lindzen, R.S. and B. Farrel. 1977. Some realistic modifications on simple climate models. J. Atmos. Sci., 34, 1487-1501.

Molnar, G. and W.-C. Wang. 1984. Dynamical heat-flux feed backs and global climate stability. Ann. Glaciol., 5, 106-110.

Newkirk, G., Jr. 1980. Solar luminosity on time scales of $10^{5}$ years to $10^{9.6}$ years. Geochim. Cosmochim. Acta, 13, 293-320.

North, G. R., R. F. Cahalan and J. A. Coakley, Jr. 1981. Energy balance climate models. Rev. Geophys. Space Phys., 16, 465-489.

Owen, T., R. D. Cess and V. Ramanathan. 1979. Enhanced $\mathrm{CO}_{2}$ greenhouse to compensate for reduced solar luminosity on early Earth. Nature, 277, 640642.

Peng, L., M.-D. Chou and A. Arking. 1987. Climate warming due to increasing atmospheric $\mathrm{CO}_{2}$ : simulations with a multilayer coupled atmosphere ocean seasonal energy balance model. 7. Geophys. Res., 92(D5), 5505-5520.

Robock, A. 1980. The seasonal cycle of snow cover, sea ice and surface albedo. Mon. Weather Rev., 108, 267-285.

Sagan, C. and G. Mullen. 1972. Earth and Mars: evolution of atmosphere and surface temperatures. Science, 177, $52-56$.

Semtner, A.J., Jr. 1976. A model for the thermodynamic growth of sea ice in numerical investigations of climate. 7. Phys. Oceanogr., 6 (3), 379-389.

Stone, P. H. and M.-S. Yao. 1990. Development of a two-dimensional, zonally averaged, statistical-dynamical model. Part III. The parameterization of eddy fluxes of heat and moisture. 7. Climate, 3, 726-740.

Wang, W.-C., G. Molnar, T. P. Mitchell and P. H. Stone. 1984. Effects of dynamical heat fluxes on model climate sensitivity. J. Geophys. Res., 89 (D3), 46994711.

Wang, W.-C., G. Molnar, M. K. W. Ko, S. Goldenberg and N. D. Sze. 1990. Atmospheric trace gases and global climate: a two-dimensional model study. Tellus, 426, 149-161.

MS received 23 November 1993 and in revised form 2 May 1994 